\title{
Triaging Inpatient Admissions: an Opportunity for Resident Education
}

\author{
Emily S. Wang, $M D^{1,2}$, Sadie Trammell Velásquez, $M D^{1,2}$, Christopher J. Smith, $M D^{3}$, \\ Tabatha H. Matthias, DO ${ }^{3}$, David Schmit, MD ${ }^{1,2}$, Sherwin Hsu, MD , and Luci K. Leykum, MD, MBA, \\ $\mathrm{MSc}^{1,2}$
}

'Department of Medicine, South Texas Veterans Health Care System, San Antonio, TX, USA; ${ }^{2}$ Division of General and Hospital Medicine, University of Texas Health Science Center at San Antonio, San Antonio, TX, USA; ${ }^{3}$ Division of Hospital Medicine, University of Nebraska Medicine Center, Omaha, NE, USA; ${ }^{4}$ Department of Medicine, Olive View - University of California Los Angeles Medical Center, Los Angeles, CA, USA.

In the context of internal medicine, "triage" is a newly popularized term that refers to constellation of activities related to determining the most appropriate disposition plans for patients, including assessing patients for admissions into the inpatient medicine service. The physician or "triagist" plays a critical role in the transition of care from the outpatient to the inpatient settings, yet little literature exists addressing this particular transition. The importance of this set of responsibilities has evolved over time as health systems become increasingly complex to navigate for physicians and patients. With the emphasis on hospital efficiency metrics such as emergency department throughput and appropriateness of admissions, this type of systems-based thinking is a necessary skill for practicing contemporary inpatient medicine. We believe that triaging admissions is a critical transition in the care continuum and represents an entrustable professional activity that integrates skills across multiple Accreditation Council for Graduate Medical Education (ACGME) competencies that internal medicine residents must master. Specific curricular competencies that address the domains of provider, system, and patient will deliver a solid foundation to fill a gap in skills and knowledge for the triagist role in IM residency training.

KEY WORDS: medical education-graduate; medical educationcurriculum; hospital medicine; care transitions; patient throughput.

J Gen Intern Med 34(5):754-7

DOI: $10.1007 / \mathrm{s} 11606-019-04882-2$

() Society of General Internal Medicine 2019

\section{INTRODUCTION}

Transitions of care, defined as "the movement of patients between health care practitioners, settings, and home as their condition and care needs change,"1 have been identified as critically important for patient safety and represent one of the

Presentations Content from this manuscript was presented as a workshop at AAIM Academic Internal Medicine Week 2018 in San Antonio, Texas, and as poster presentations at Society of General Internal Medicine National Meeting 2018 in Denver, Colorado.

Published online April 16, 2019 targeted initiatives of the Joint Commission Center for Transforming Health Care aims. ${ }^{2}$ In recognition of the possibility of poor outcomes, many societies including the American College of Physicians, Society of Hospital Medicine, and Society of General Internal Medicine have worked collaboratively to issue consensus policy statements and task force recommendations on transitions of care and handoffs. ${ }^{3,4}$ To date, the body of literature has predominantly been focused on inpatient to outpatient transitions and inpatient to inpatient transitions, in particular intra-unit transfers. Little attention has been given to the process that occurs as the patients transition from the outpatient to inpatient settings. ${ }^{4}{ }^{5}$ With the "divorce of inpatient and outpatient care" 6 and the rise of the emergency department (ED) as a gateway for hospital admissions for older adults, ${ }^{7}$ the role of admitting patients from the clinic or ED has been transitioned to inpatient physicians. A recent survey of hospital leaders found that, other than caring for general medical patients, the greatest clinical need for inpatient physicians included "screening medical admissions from the emergency room (ER) for appropriateness of admission and triaging to appropriate level of care" and "triaging patients from an outside hospital." 8

The term triage has evolved over time. Initially, this term was defined as sorting of patients in mass casualty situations, while in modern medicine it is defined in emergency medicine (EM) literature as a dynamic three-phase process of a brief clinical assessment that prioritizes the time and sequence a patient should be seen prior to arriving in the ER. ${ }^{9}$ From the hospitalist perspective, triaging refers to assessing patients for inpatient admission, determining the appropriate level of care, coordinating care transitions from the ED, and managing hospital throughput. Recent years have also seen growing expectations of efficiency from hospital administrators, with hospitalists doing more to facilitate ED admissions. While this role expansion may demonstrate hospitalists' effectiveness in patient flow management, the skill set associated with triaging may be different from those required for either outpatient or inpatient care. Patient flow and bed management are increasingly important considerations in the admissions process. ${ }^{10-12}$ Some facilities have developed hospital medicine (HM)-ED teams to combat overcrowding 
and prolonged boarding in the ED. ${ }^{13}$ Managing patient throughput has improved ED throughput for both intensive care units and general medicine patients. ${ }^{13-15}$

Despite the growing need to develop skill in performing hospital triage, the historical responsibility of assessing inpatient admissions by the on-call internal medicine (IM) resident has been or is being shifted to faculty at many institutions. In our on-going multi-site collaborative study at ten academic institutions across the USA, the triagist or the admission point of contact was a faculty physician over $75 \%$ of the time. ${ }^{16}$ With hospitalists now numbering over 50,000 (more than twice that of any IM sub-specialty $)^{17}$ and a growing number of programs offering hospitalist-focused clinical rotations, ${ }^{18}$ we believe it is critical for IM residency programs to integrate triage training into their curricula. Triage responsibilities encompass many of the internal medicine end of training entrustable professional activities (EPAs) ${ }^{19}$ such as: manage transitions of care, lead and work within interprofessional health care teams, and manage care of patients with acute complex diseases across multiple care settings. Providing education in triage training to our learners would offer the opportunity to meaningfully address ACGME/American Board of Internal Medicine Milestones. ${ }^{20}$ In the following paragraphs, we will outline how these core competencies relate to the triagist role to serve as a guide for curriculum development (Fig. 1).

\section{Curricular Competencies for the Triagist}

Interpersonal communication and professionalism is the first central concept of the triagist role that is critical to master to become an effective and efficient triagist. Inter-unit handoff communication between EM and HM providers at the time of hospital admission is often sub-optimal and may endanger patient safety. ${ }^{21,22}$ Structured admission handoff processes can improve communication quality, ${ }^{23,} 24$ but are not commonly utilized. ${ }^{25}$ Triage curricula provide opportunity to teach residents best practice recommendations for admission handoff communication, which differs in style, form, and content when compared to more familiar end-ofshift shift handoffs. ${ }^{26}$ The decision to admit a patient can be fraught with conflict as EM and IM may have divergent expectations. ${ }^{26-28}$ While internists generally expect a diagnosis or course of progression from ED counterparts, the ED may view their role as stabilization and safe disposition of the patient. ${ }^{21,}{ }^{26}$ Inpatient physicians may become frustrated when the evaluations by EM physicians do not meet their expectations. ${ }^{29}$ Appreciating the differences between IM and EM is an important concept for mitigating conflict and negotiating a care plan. Triage curricula should teach and assess residents on their ability to foster collaborative interdisciplinary and interprofessional dialogue that focuses on creating a shared mental model of patient care.

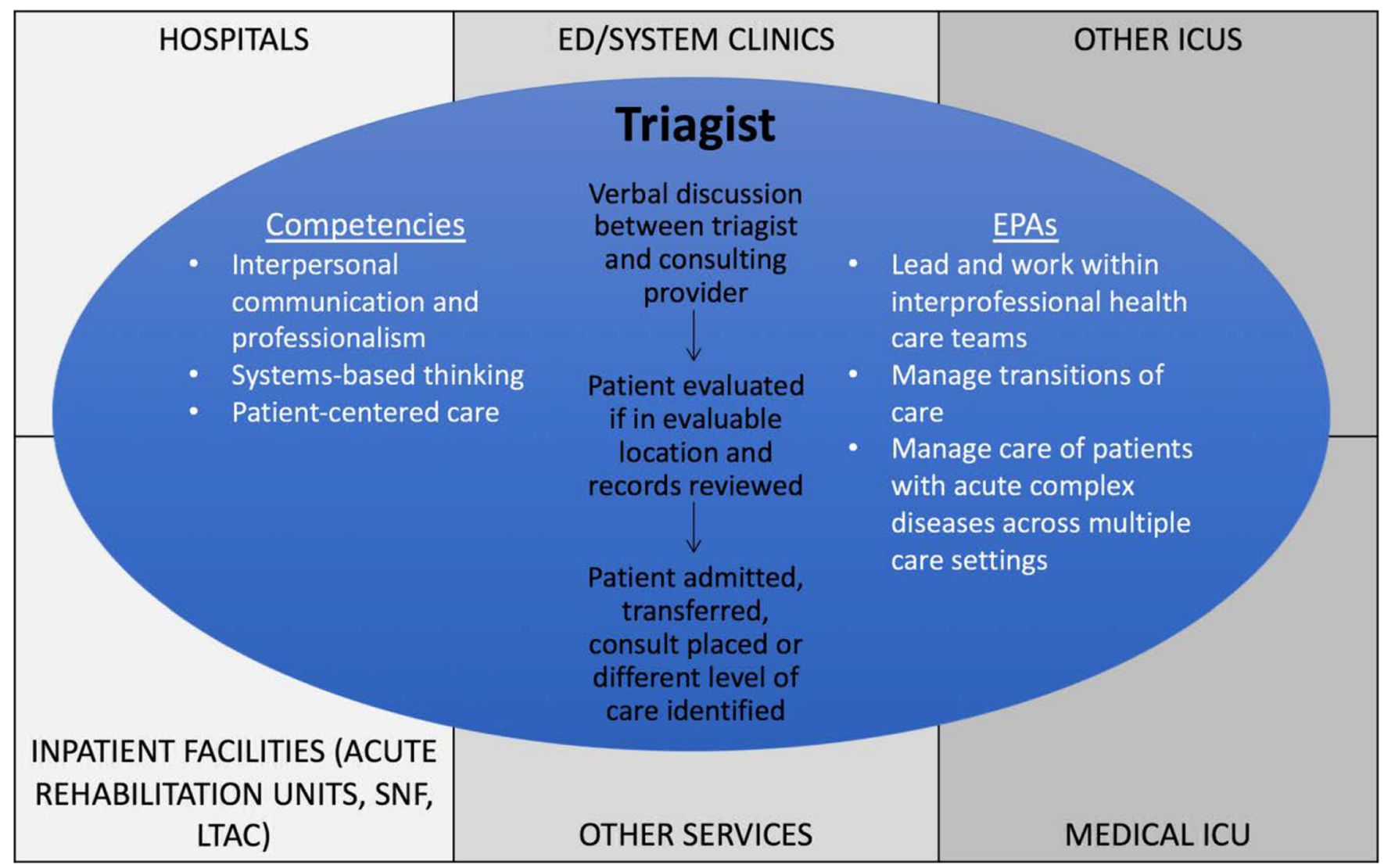

Figure 1 Curricular concept model for triagist role 
Systems-based thinking and understanding the health care system as it relates to the triagist role can introduce residents to many foundational concepts important to health care organizations such as clinical microsystems. Clinical microsystem is defined as a small, interdependent group of people who work together regularly to provide care for a specific group of patients. ${ }^{30}$ The triagist is the pivotal role at the intersection of many clinical microsystems such as the ED, inpatient medicine services, and outpatient primary care. We can assist residents in learning the initial concepts and elements of the systems of patient care. ${ }^{31,32}$ For example, residents can analyze from the systems perspective of the triagist using the goals or "Ps" of the clinical microsystems: (1) Purpose- to facilitate safe transfer of patients from the outpatient to the inpatient setting; (2) Patients - the population we are assessing for possible admission; (3) Professionals - health care team members working together in this transition of care; and (4) Processes - understanding the admission pathway and the level of care criteria necessary for efficient patient flow. ${ }^{31}$ This understanding will lead to familiarity and demonstrate how effective relationships among a range of health care team members, such as patient flow coordinators, allows for timely management of hospital resources. ${ }^{14,} 33$ Additionally, residents begin to appreciate the effects of ED and hospital overcrowding and impact on patient care. They develop a deeper understanding of the importance in finding alternative solutions to unnecessary admissions by enlisting other health care team members such as social workers and case managers, which can improve patient and provider satisfaction. ${ }^{34}$ Allowing residents to work through conflicting opinions and negotiate solutions provides them with first-hand knowledge of our interconnected health care system.

Patient-centered care is the final curricular domain. The transition from the outpatient to inpatient setting is a vulnerable and confusing time for patients and their families, especially as processes for admissions are locally specific and may even differ between services within the same hospital. ${ }^{22}$ Clear and empathic communication at this juncture is crucial and essential. Communication regarding the reason for admission and test results improved patient satisfaction, but patients also felt it was necessary for physicians to express empathy. ${ }^{35,}{ }^{36}$ In addition, patients have clear expectations regarding hospital admissions and want greater autonomy in medical decision-making. ${ }^{36,37}$ With the nation-wide focus on patient-centered care and prior research showing a targeted curriculum for patient communication improved patient satisfaction and resident education, a defined triagist resident curriculum is a perfect opportunity for teaching and assessing collaborative patient care skills. ${ }^{38}$

Understanding that transitioning patients from the outpatient to the inpatient setting is fraught with complexity, it has been recognized in EM literature as a challenging transition as well. Conflict prevention, communicating across specialties, and understanding differences in priorities between IM and EM have been important concepts that are highlighted in the EM literature. ${ }^{19,}{ }^{23-26}$ In addition, there have been calls for collaboration by leaders in EM and IM to partner in finding solutions in improving continuity of patient care. ${ }^{26,}{ }^{39} \mathrm{EM}$ residency education has also found a lack of standardized approaches to training in transitions of care, in particular the ED to the inpatient handoff. ${ }^{40-42}$ Although there are areas of overlap in EM and IM graduate medical education (GME) for the triagist role, such as interprofessional communication, we propose there are perspectives that are unique to IM GME. Systems-based thinking and understanding the health care system as it relates to the triagist role has not been defined or discussed in the literature. With increased emphasis on hospital efficiency measures focused on appropriate utilization management and resource allocation, determining the appropriate bed for a patient such as intensive care vs. inpatient admission vs. observation has implications beyond the clinical care of the patient. Oftentimes, understanding the significance of these decisions requires the perspective of physicians who care for the patient in the inpatient setting.

We define the triagist as a physician who assesses and evaluates potential admissions to the inpatient medicine service. In addition, we found there is a gap in the literature that specifically addresses the responsibilities of this role. "Hospitalist quarterback" or "active bed manager" are names that have also been used to describe some of the activities linked to this position; however, the complexity of balancing the patient, system, and provider domains requires a high degree of cognitive workload. Residents need exposure to the triage role to work towards mastery of these EPAs for unsupervised practice. Many may argue that only "hands-on" experience will appropriately prepare learners to develop this skill set; however, we believe that there needs to be a step-wise approach beginning with defining competencies for a specific IM resident triage curriculum focusing on (1) interprofessional communication, (2) systems-based thinking, and (3) patientcentered care. This will provide the foundation to develop, recognize, and identify observable activities for resident education in triage and strive towards outcome-based medical education that integrates our educational and clinical missions. ${ }^{43,} 44$

Acknowledgements: The research reported here was supported by the Department of Veterans Affairs, Veterans Health Administration. Author salary support is provided by the South Texas Veterans Health Care System and by the Division of Hospital Medicine at the University of Texas Health Science Center San Antonio.

Corresponding Author: Emily S. Wang, MD; Department of Medicine South Texas Veterans Health Care System, San Antonio, TX, USA (e-mail: wange@uthscsa.edu).

Funding This work was supported in part by a 2017 Alliance for Academic Internal Medicine (AAIM) Innovation Grant.

\section{Compliance with Ethical Standards:}

Conflict of Interest: The authors declare that they have no conflicts of interest. 
Disclaimer: The views expressed in this article are those of the authors and do not necessarily reflect the positions or policies of the Department of Veterans Affairs or collaborating institutions.

Presentations: Content from this manuscript was presented as a workshop at AAIM Academic Internal Medicine Week 2018 in San Antonio, Texas, and as poster presentations at Society of General Internal Medicine National Meeting 2018 in Denver, Colorado.

Publisher's Note: Springer Nature remains neutral with regard to jurisdictional claims in published maps and institutional affiliations.

\section{REFERENCES}

1. Transitions of Care: The need for a more effective approach to continuing patient care. 2012. 2018, at https://www.jointcommission.org/assets/ 1/18/Hot_Topics_Transitions_of_Care.pdf.

2. Joint Commission Center for Transforming Healthcare releases targeted solutions tool for hand-off communications. Jt Comm Perspect. 2012;32:1, 3.

3. Arora VM, Manjarrez E, Dressler DD, Basaviah P, Halasyamani L, Kripalani S. Hospitalist handoffs: a systematic review and task force recommendations. J Hosp Med. 2009;4:433-40.

4. Snow V, Beck D, Budnitz T, et al. Transitions of Care Consensus policy statement: American College of Physicians, Society of General Internal Medicine, Society of Hospital Medicine, American Geriatrics Society, American College Of Emergency Physicians, and Society for Academic Emergency Medicine. J Hosp Med. 2009;4:364-70.

5. Luu NP, Pitts S, Petty B, et al. Provider-to-provider communication during transitions of care from outpatient to acute care: a systematic review. J Gen Intern Med. 2016;31:417-25.

6. Pham HH, Grossman JM, Cohen G, Bodenheimer T. Hospitalists and care transitions: the divorce of inpatient and outpatient care. Health Aff (Millwood). 2008;27:1315-27.

7. Greenwald PW, Estevez RM, Clark S, Stern ME, Rosen T, Flomenbaum N. The ED as the primary source of hospital admission for older (but not younger) adults. Am J Emerg Med. 2016;34:943-7.

8. Vasilevskis EE, Knebel RJ, Wachter RM, Auerbach AD. California hospital leaders' views of hospitalists: meeting needs of the present and future. J Hosp Med. 2009;4:528-34.

9. Robertson-Steel I. Evolution of triage systems. Emerg Med J. 2006;23:154-5.

10. Apker J, Mallak LA, Applegate EB 3rd, et al. Exploring emergency physician-hospitalist handoff interactions: development of the Handoff Communication Assessment. Ann Emerg Med. 2010;55:161-70.

11. Briones A, Markoff B, Kathuria N, et al. A model of a hospitalist role in the care of admitted patients in the emergency department. J Hosp Med. 2010;5:360-4.

12. Holroyd BR, Bullard MJ, Latoszek K, et al. Impact of a triage liaison physician on emergency department overcrowding and throughput: a randomized controlled trial. Acad Emerg Med. 2007;14:702-8.

13. Chadaga SR, Shockley L, Keniston A, et al. Hospitalist-led medicine emergency department team: associations with throughput, timeliness of patient care, and satisfaction. J Hosp Med. 2012;7:562-6.

14. Howell E, Bessman E, Kravet S, Kolodner K, Marshall R, Wright S. Active bed management by hospitalists and emergency department throughput. Ann Intern Med. 2008;149:804-11.

15. Howell E, Bessman E, Marshall R, Wright S. Hospitalist bed management effecting throughput from the emergency department to the intensive care unit. J Crit Care. 2010;25:184-9.

16. Abstracts from the 2017 Society of General Internal Medicine Annual Meeting. J Gen Intern Med. 2017;32:83-808.

17. Wachter RM, Goldman L. Zero to 50,000 - The 20th Anniversary of the Hospitalist. N Engl J Med. 2016;375:1009-11.

18. Ludwin S, Harrison JD, Ranji S, Sharpe BA, Kneeland P. Training Residents in Hospital Medicine: The Hospitalist Elective National Survey. J Hosp Med. 2018.

19. Internal Medicine End of Training EPAs. 2012. 2018, at https://www.im org/resources/ume-gme-program-resources/milestones/end-epas.

20. The Internal Medicine Milestone Project. 2015. 2018, at http://www. acgme.org/portals/0/pdfs/milestones/internalmedicinemilestones.pdf.
21. Horwitz LI, Meredith T, Schuur JD, Shah NR, Kulkarni RG, Jenq GY. Dropping the baton: a qualitative analysis of failures during the transition from emergency department to inpatient care. Ann Emerg Med. 2009;53:701-10 e4.

22. Smith CJ, Britigan DH, Lyden E, Anderson N, Welniak TJ, Wadman MC. Interunit handoffs from emergency department to inpatient care: a cross-sectional survey of physicians at a university medical center. $\mathrm{J}$ Hosp Med. 2015;10:711-7.

23. Benjamin MF, Hargrave $\mathbf{S}$, Nether K. Using the Targeted Solutions Tool(R) to Improve Emergency Department Handoffs in a Community Hospital. Jt Comm J Qual Patient Saf. 2016;42:107-18.

24. Smith CJ, Buzalko RJ, Anderson N, et al. Evaluation of a novel handoff communication strategy for patients admitted from the Emergency Department. West J Emerg Med. 2018;19:372-9.

25. Kessler C, Scott NL, Siedsma M, Jordan J, Beach C, Coletti CM. Interunit handoffs of patients and transfers of information: a survey of current practices. Ann Emerg Med. 2014;64:343-9. e5.

26. Beach C, Cheung DS, Apker J, et al. Improving interunit transitions of care between emergency physicians and hospital medicine physicians: a conceptual approach. Acad Emerg Med. 2012;19:1188-95.

27. Chan T, Bakewell F, Orlich D, Sherbino J. Conflict prevention, conflict mitigation, and manifestations of conflict during emergency department consultations. Acad Emerg Med. 2014;21:308-13.

28. Gibson SC, Ham JJ, Apker J, Mallak LA, Johnson NA. Communication, communication, communication: the art of the handoff. Ann Emerg Med. 2010;55:181-3.

29. Gleeson SK, O'Mahony SP, Berman L, et al. Reducing patient retriage and improving physician attitudes by provision of consensus workup guidelines in the emergency department. JCOM. 2009; 16.

30. Clinical Microsystem Assessment Tool. 2018, at http://www.ihi.org/ resources/Pages/Tools/ClinicalMicrosystemAssessmentTool.aspx.

31. Barach $\mathbf{P}$, Johnson JK. Understanding the complexity of redesigning care around the clinical microsystem. Qual Saf Health Care. 2006;15 Suppl 1:110-6.

32. Colbert CY, Ogden PE, Ownby AR, Bowe C. Systems-based practice in graduate medical education: systems thinking as the missing foundational construct. Teach Learn Med. 2011;23:179-85.

33. Southard PA, Hedges JR, Hunter JG, Ungerleider RM. Impact of a transfer center on interhospital referrals and transfers to a tertiary care center. Acad Emerg Med. 2005;12:653-7.

34. Daniels LM, Sorita A, Kashiwagi DT, et al. Characterizing potentially preventable admissions: a mixed methods study of rates, associated factors, outcomes, and physician decision-making. J Gen Intern Med. 2018;33:737-44.

35. Downey LV, Zun LS. The correlation between patient comprehension of their reason for hospital admission and overall patient satisfaction in the emergency department. J Natl Med Assoc. 2010;102:637-43.

36. Roh H, Park KH. A scoping review: communication between emergency physicians and patients in the emergency department. J Emerg Med. 2016;50:734-43.

37. Whyte E, Goodacre s. Patient expectations of emergency hospital admission: a cross-sectional questionnaire survey. Eur J Emerg Med 2016;23:203-7.

38. Ratanawongsa N, Federowicz MA, Christmas C, et al. Effects of a focused patient-centered care curriculum on the experiences of internal medicine residents and their patients. J Gen Intern Med. 2012;27:473-7.

39. Pollack CV Jr., Amin A, Talan DA. Emergency medicine and hospital medicine: a call for collaboration. Am J Med. 2012;125:826 e1-6.

40. Gallahue FE, Betz AE, Druck J, Jones JS, Burns B, Hern G. Ready for discharge? A survey of discharge transition-of-care education and evaluation in emergency medicine residency programs. West J Emerg Med. 2015;16:879-84

41. Kessler C, Shakeel F, Hern HG, et al. A survey of handoff practices in emergency medicine. Am J Med Qual. 2014;29:408-14.

42. Lee S, Jordan J, Hern HG, et al. Transition of care practices from emergency department to inpatient: survey data and development of algorithm. West J Emerg Med. 2017; 18:86-92.

43. Chen FM, Bauchner H, Burstin H. A call for outcomes research in medical education. Acad Med. 2004;79:955-60.

44. O'Malley PG, Pangaro LN. Research in medical education and patientcentered outcomes: shall ever the twain meet? JAMA Intern Med. 2016;176:167-8. 